\section{Primary pure signet-ring cell carcinoma of the anus: a case report with immunohistochemical study}

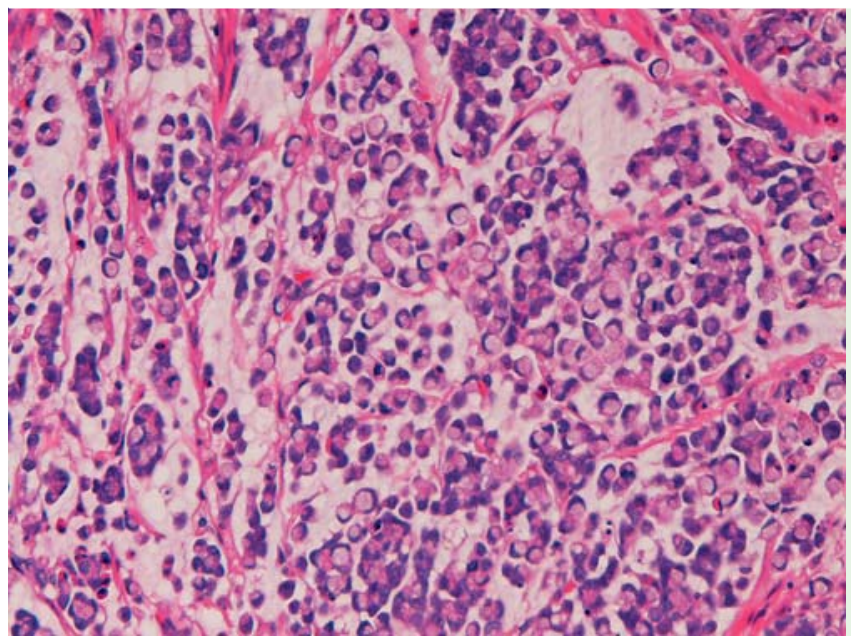
specimen from the anus. High power photomicrograph shows apparent pure signet-ring cell carcinoma (hematoxylin and eosin).

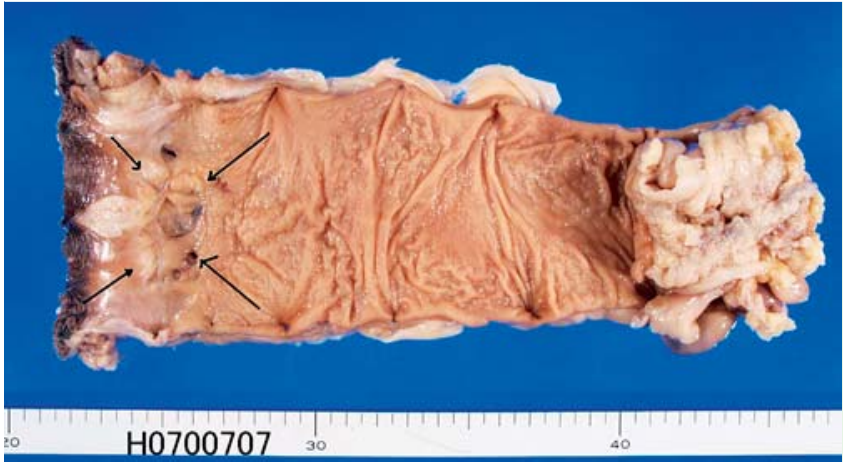

Fig. 2 Surgical resected specimen. Irregular mucosa after polypectomy (arrows) is seen in the anus.

Although several cases of signet-ring cell carcinoma (SRCC) in the colorectum have been reported $[1,2]$, there have been no reports of SRCC in the anus. The case presented here is the first reported case of primary pure SRCC of the anus.

A 49-year-old man presented with anal bleeding. Colon endoscopy revealed a polyp in the anus, and polypectomy was performed The polypectomy specimen showed pure SRCC ( $\bullet$ Fig. 1). Because the surgical margins were positive, a Miles operation was performed ( Fig.2). Regional lymph node metastases were present. Macroscopically, the anus showed irregular mucosa ( Fig.2). Microscopically, pure SRCC was recognized. Histochemically, the SRCC showed mucins. An immunohistochemical study was performed using Dako's EnVision method [3, 4]. Immunohistochemically, the SRCC cells were positive for cytokeratin AE1/3, cytokeratin CAM5.2, cytokeratin 8 (CK8), cytokeratin 18 (CK18), cytokeratin 19 (CK19), epithelial membrane antigen (EMA), carnegative for cytokeratin 5/6 (CK5/6) CK34ßE12, cytokeratin 7 (CK7), cytokeratin 14 (CK14), cytokeratin 20 (CK20), CD56, neuron-specific enolase, chromogranin, p63, vimentin, thyroid transcription factor 1 (TTF-1), mucin 5AC (MUC5AC), and mucin 6 (MUC6). The patient died of carcinomatosis 5 months after the operation.

This is the first reported case of primary SRCC of the anus. The author speculates that in this case the SRCC arose from malignant transformation of the anal glands. The cytokeratin profiles showed low-molecular-weight cytokeratins. CDX2 immunostaining was positive, compatible with a primary tumor of the anus. The tumor also stained positive for synaptophysin, suggesting that it has neuroendocrine features. It is not a signet-ring cell carci-
Fig. 1 Polypectomy

noid, because immunostaining for other neuroendocrine markers (CD56, chromogranin, neuron-specific enolase) was negative. EMA was expressed and vimentin was not expressed, suggesting that the tumor is epithelial in origin. p53 was expressed, suggesting p53 gene mutation in the present case. Ki-67 labeling was high in the tumor, suggesting high cellproliferative activity. CEA and CA19-9 immunostaining was positive, indicating that these molecules are produced by SRCC cells. The SRCC in this case expressed products of MUC1 and MUC2 apomucins, but did not express the product of MUC5AC and MUC6 genes, suggesting that the MUC1 and MUC2 apomucins are operative. Patient survival in SRCC is poor $[1,2]$, as it was in the present case.

Endoscopy_UCTN_Code_CCL_1AD_2AJ

Competing interests: None

\section{T. Terada}

Department of Pathology, Shizuoka City Shimizu Hospital, Shizuoka, Japan

\section{References}

1 Tung SY, Wu CS, Chen PC. Primary signet-ring cell carcinoma of colorectum: an age- and sex-matched controlled study. Am J Gastroenterol 1996; 91: 2195-2199

2 Sung CO, Seo JW, Kim KM et al. Clinical significance of signet-ring cells in colorectal mucinous adenocarcinoma. Mod Pathol 2008; 21: $1533-1541$

3 Terada T, Kawaguchi M, Furukawa $K$ et al. Minute mixed ductal-endocrine carcinoma of the pancreas with predominant intraductal growth. Pathol Int 2002; 52: 740-746

4 Terada T, Kawaguchi M. Primary clear cell adenocarcinoma of the peritoneum. Tohoku J Exp Med 2005; 206: 271 - 275
Bibliography

Dol http://dx.doi.org/

10.1055/s-0031-1291516

Endoscopy 2014; 46: E347

(c) Georg Thieme Verlag KG

Stuttgart · New York

ISSN 0013-726X

Corresponding author

\section{T. Terada, MD, PhD}

Department of Pathology

Shizuoka City Shimizu Hospital

Miyakami 1231 Shimizu-Ku

Shizuoka 424-8636

Japan

Fax: +81-54-3341173

piyo0111jp@yahoo.co.jp 